\title{
Paid Promotion on Facebook: AN Analysis Employing a Data Processing Method
}

\author{
P. Shirisha, A. Laxmiprasanna
}

\begin{abstract}
: this document bases on researching piece of remunerated vehicles on proposes \& facebook a social control recommendation to pull in paid appearances' to relate in going with cloudy number of individuals from conceivable with the best obligation. Fake neural structures, garson's algorithmic program, and strengthen vector machine coefficient were adjusted evaluate plan properties. The results show that to the level of individuals came to, paid spreads ar fundamentally nine. $52 \%$ fitting, withdrew and twenty four. $35 \%$ for submit hour, 16.eighty five\% for resolute sheet like, \& $16.44 \%$ pro kind of creation. Concerning level of comments, likes, and offers, paid advancing contributes ten.46\%, $19.51 \%$, and $15.55 \%$ affiliation, severally. Inspiration driving truth, the huge degrees of age stimulates from misuse paid degrees of progress and nonpaid sees ar surveyed and picked. This paper gives a social control suggestion to offering director to help the paid headway execution of conspiracy facebook pages.
\end{abstract}

Key words : social media, data getting ready, paid sorts of progress, artificial neural networks.

\section{INTRODUCTION}

I In cutting-edge-day time, societal networks have be one in all mainly stated conversation systems amongst university university students .Social media offers numerous opportunities like accomplishing bent on, interacting, fresh customers with day-day introducing, costumers, and promoting particular merchandise otherwise services). utilize of societal networks as a promoting \& advertising and marketing instrument have been well referred to since a showed, effective instrument to apprehend innumerable clients advertising and marketing and advertising profits inflated from $\$ 36$ million in 2002 - $\$$ six billion in 2012 \& is predicted to growth extra inside the destiny

In mid 2018, there have been 132.7 million web clients in Indonesia, and ninetieth of these web clients were dynamic on Facebook. This information uncovers gigantic open gateways for on-line business through $\mathrm{Fb}$ in Indonesia. in favor of endeavors that need toward fuse their thing to Indonesia, abuse $\mathrm{Fb}$ since a web distributer is maybe a not too terrible structure. Furthermore, twenty seventh of the investigated respondents in driving evaluations show that Facebook is that the raving accomplishment contraption for relationship with under 500 staff. Additionally, most non-state kept up colleges in Malaysia have assertion online life to pull in new

Revised Manuscript Received on December 30, 2019.

P. Shirisha, Department of CSE, Malla Reddy College of Engineering, Women, Hyderabad, Telangana, India. Shirishasree19@gmail.com

A. Laxmiprasanna, Department of CSE, Malla Reddy College of Engineering, Women, Hyderabad, Telangana, India.

laxmiprasanna1992@gmail.com understudies . Facebook as an advert instrument has 2 key approaches to manage supervise push thing or affiliations: standard improvement and paid progression. Through trademark progress, clients will pass on free coalition pages or individual fan pages, pack exchanges, or maybe important records with none charge. Regardless, on the off chance that affiliations resolve to utilize typical advancement (with no piece), by then the corporate fan pages ought to have different supporters and Facebook heading some particular business polices. then again, if firms a zone unit engineered to pay cash on $\mathrm{Fb}$ remunerated promotions ,compass of corporate to possible clients is capably clearing \& doesn't depend upon and gigantic on fanatics of association admirer page. Paid developments advantages corporate since of possible clients are an inconceivable bit of the time focused on while not constrainment. Incidentally, different specialists have found that Facebook paid advancements don't arrive at new clients successfully (for example Margarida).

Since paid movements don't transmit an impression of being enable, each call ought to be sensible. The unavoidable eventual outcomes of each call should be in a general sense overviewed. information arranging gives some bewildering assessment approaches to manage regulate looking into changed enlightening varieties .Moreover, information overseeing is perceived to be a solid mechanical party for restricting information from forefront and bounteous online life information. Man-made comprehension could be a set \{of knowledge|of information\} tunneling ways for isolating such illuminating records. Fake neural structures (ANNs) are wide utilized as information preparing contraptions for online life information .

This appraisal expected to audit the relationship of Facebook paid developments to the degree of contacted public \& to pick vehicle duty of every position with misuse ANN's. Garson's algorithmic standard be wont to understand ANN results. in addition, near assist selling supervisors in moving the presentation of remunerated dispersals, an social control proposition concerning age was anticipated by abuse support vector machine weight (SVM). The social control recommendation contains a position of the data factors fortified their association with win in different people and lift duty of each paid creation.

The unavoidable outcomes of the evaluation uncover that paid headways addresses under nine. $52 \%$ of centrality to mean time length post reach. Segregated and undeniable data sources, similar to post hour, complete page affinities, and sorts of courses, the degree of paid developments inside the post's timespan was less persuading. 
Paid movements have ten.46\%, $15.55 \%$, and $19.51 \%$ of the this paper, a social control suggestion framework kept up the vitality of every sub feature (Table 1) is anticipated to get better compensated creation execution. fundamental sub features square measure by afterward thought of considering the manner by which that the most basic factors in up unwavering time length reach and full scale responsibility. Along these lines, this noteworthiness order of sub frames would be thought of once creation an creation call pro business during coalition's $\mathrm{Fb}$ sheet. undertaking call would show position point, position style, position set, \& express linked ways. Complete clarification be given inside social control suggestion zone.

\section{RELATED WORK}

hypothetically, an laptop ought to effort higher than an person's intelligence. elements within pc alter outstanding process memory and ability. though, human being mind is reconciling \& continue to be told with therefore will administer itself throughout its extended time. These flexible individuality be enforced in ANN's pro information processing

Figure 1 ANNs results using RapidMineroperations (e.g., class and prediction). ANNs carries with it 3 sorts of layer: enter layer, output layers \&hidden layers. the ones consistent businesses of mock neurons broadcast records thru severa associations.

Effectiveness of ANN's for evaluation of societal medium acknowledge has been well-attempted with the useful beneficial aid of a few researchers. ANNs mounted to exist controlling tackle in predict customers' feelings via societal medium submit reaction .in records processing area, non linear preparation abilities of ANNs are drastically called a superb tool specifically in massive and complicated understanding knowledge set operations . therefore, at some point of this assessment we commonly have a tendency to use ANN's to research connexion of compensated commercials on $\mathrm{fb}$. due to ANN's gene awesome superior hidden layers and output weights, Garson's algorithmic software end up wont to interpret the output weights \& hidden layers.Garsons algorithmic software application software program have grow to be fictitious with the useful resource of way of Garson (1991) so modified with the beneficial beneficial aid of this check used Garson's algorithmic software program to get the relative importance of each community input. This relative significance is calculated thru the usage of three essential steps. the number one step is to reproduce concealed nerve output weights \& mobile weights. the second pace is to estimate relation donation of every concealed nerve mobile. 0.33 steps is to determine relation importance of input through relation donation consequences. in a few unspecified time within the destiny of this check, for determinant significance of subinput\& every enter of ebook tendencies inclinations, SVM coefficient have become applied. SVM considers an statistics set as a -commercial enterprise business enterprise splendor drawback and determines the simplest hyper aircraft. significance of remarks, offers, and likes, severally. during

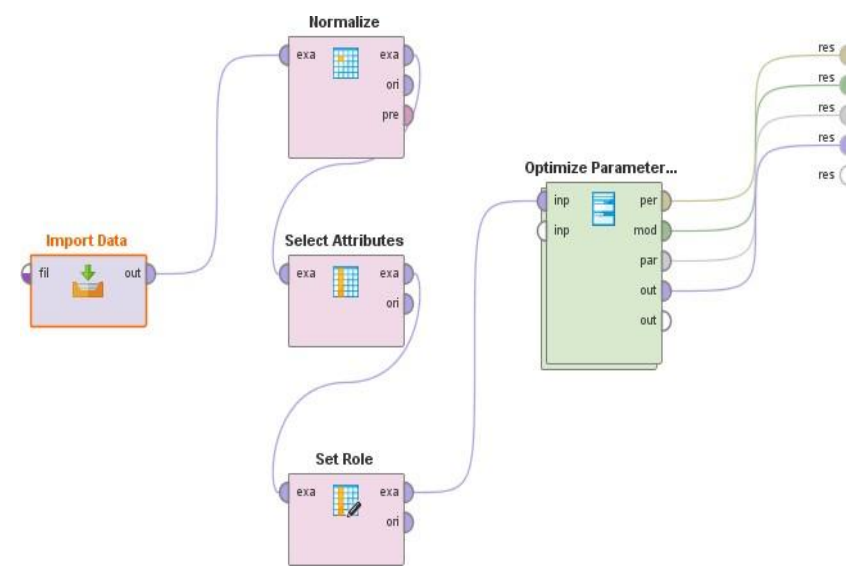

Figure 2. Data mining and optimize
parameter processes Using Rapid Miner
(Grid)

\section{DATA AND METHODOLOGY}

The acknowledge have become obtain starting an UCI facts put plus consisted of 5 hundred post positioned out since a far-famed splendor enterprise corporation (Moro et al., 2016). This acknowledge turn out to be processed with ANNs to live the general widespread normal overall presentation of remunerated classified ad. To understand outcomes of ANN's, Garson's additives become use to make certain correctness of the ANNs, a grid method end up accustomed affirm the amount of education cycles. furthermore, in advance than the grid approach changed into run, $\{$ the acknowledge|the statistics|the statistics $\}$ have end up split into 2 halfs; the primary half of of come to be used as education statistics (70\%) and moreover the second one aspect grow to be used as test records $(30 \%)$. a whole data \{processing technique exploitation Rapid Miner is confirmed in Fig. 2. facts ar delineate in table one. First, seven input variables had been standardized through exploitation $Z$ transformation and moreover the variable quantity $(\mathrm{Y})$ emerge as preprocessed into the range exploitation the system:

$$
\mathrm{m}=\mathrm{yn}-\min (\mathrm{Y})
$$

Then, five hundred posts' facts were wont to build up the hidden layers and output weights. To extra have a have a have a have a look at the paid commercials' effectiveness, we have a propensity to used a sampling method to select out out and take a look at 139 paid and 139 nonpaid advertisements. At the realization of this assessment, a social manage method at the manner to place up a manual became obtained thru feed 7 inputs into the tool and reading them in terms of SVM weight. This social manipulate implication is aimed to help promoting managers in deciding on ad type, ad elegance, and ad time, as fast as organization enterprise their enterprise organisation $\mathrm{fb}$ pages. 
due to the cause emerge as to are seeking out out the nice technique for paid publications, 139 publications that used paid advertisements had been idea-approximately.

\begin{tabular}{ll}
\hline Features & Role \\
\hline Pages Total Likes & Input Variables \\
Type & Input Variables (Photo, \\
& Status, link, and Video) \\
& Input Variables (Action, \\
Category & Product, and \\
& Inspiration) \\
Post Month & Input Variables (January- \\
& December) \\
Post Weekday & Input Variables (Sunday- \\
& Saturday) \\
Post Hour & Input Variables (1-24) \\
Paid & Input Variables (1,0) \\
Total lifetime post & \\
reach & Output or label variable \\
Comments & Output or label variable \\
Likes & Output or label variable \\
Shares & Output or label variable \\
Total Interactions & Comments + likes + \\
& shares \\
\hline
\end{tabular}

\section{DISCUSSIONS AND RESULTS}

\section{Paid Ads and Total life post reach:}

We analyzed weight of every input changeable via the use of manner of mistreatment ANNs. to accumulate the exquisite feasible consequences, grid are seeking for have grow to be completed to are searching out out the maximum dependable parameters. In grid are looking for evaluation, the amount of schooling cycles become set inside range 500to10,000 cycle's. surrender result disclosed to arrangement by 1070 (table three) preparation cycle have tiniest origin endorse rectangular error. The assertion changed into use because of reality nominative shape of schooling cycle for analyze weights of 7 inputs in relevance overall attain of a placed up over its whole existence. effects proven in desk a couple of.

due to the truth the consequences of ANNs absolutely carries with it hidden somatic mobile weights and output weights, we have a propensity to completed Garson's algorithmic rule to construe hidden somatic cell weights. Outcomes of Garson's algorithmic rule ar installation in decide three. normal weight effects show that hours of acknowledge is greater critical than possibility input (Fig. three). positioned up hour makes a twenty $4.35 \%$ contribution to everyday time period located up collect; fashionable net internet web page likes of nonprivate is in second location with sixteen.80 five \% relevance; form of positioned up is in $1 /$ three vicinity with sixteen.forty four $\%$ relevance; and placed up month is in fourth location with fourteen.57\%. supported those consequences, we have a propensity to decided that paid advertisements through commercial enterprise company facebook pages completely have 9.fifty $\%$ connexion to time period famous attain of a placed up. put up hour, net internet net page well-known likes, kind, positioned up month, and put up weekday had been decided to possess extra connexion than paid advertisements to everyday time period put up gain. those outcomes display off that paid advertisements make a contribution little or no to time frame stylish advantage and placed up hour have become the foremost relevant trouble that enabled non-public to build up severa people. The implication is that an corporation need to be aware of nicely timed publishing; an corporation need to not at random placed up a submit and vend through paid commercials.

Moreover, we have a propensity to in assessment the complete obtain values of 139 posts determined out with paid commercials and some one-of-a-kind 139 posts decided out at the same time as no longer paid commercials. The evaluation unconcealed that in phrases of typical length put up collect, nonprivate promoted with paid classified ads paintings better than nonprivate at the identical time as now not paid commercials. the amount of human beings reached with paid advertisements modified into more than one,681,054 \& moreover kind of public reach even as not paid advertisements emerge as one,068,650 (Fig. 4). The non-publications private to use paid commercials acquire nineteen,288 parents on common; the non-publiccourses that do not use paid commercials acquire really seven, 688 dad and mom at the commonplace. therefore, with the aid of way of selecting to pay coins for advertisements, a supervisor will obtain pretty a hundred and fiftieth quite some functionality clients. but, this accomplishment isn't enough, due to style of humans reached does no longer assure alteration near form of genuine deal of crop. the development isn't by myself because of paid classified ads, but furthermore supported with the aid of the use of some elements like type, placed up hour, elegance (content fabric material), placed up months, page preferred like, \& publish standard. furthermore, this assessment found that position hour \& clean internet internet sheet like contain numerous connexion than compensated classified ad in ability dad and mom. consequently, if correct style of located up is printed on right time, it's going to maximum likely achieve loads of dad and mom than a positioned up that on my own is primarily based upon on paid commercials on the identical time as no longer regard for temporal order or enchantment. Extrapolating from the general weight method victimisation ANNs, 9.fifty \% of paid advertisements guide the complete period reap of a positioned up. because of this, the donation of compensated advertisements to form of people reached isn't higher than the assistance of numerous input like located up hours, page essential like, \& shape of acknowledge. consequently, if corporations gauge kind \& instance nicely their post posts need to most in all likelihood perform an prolonged way higher in achieving severa parents than the posts of groups that clearly bear in mind paid commercials.

\section{Paid ads and Comments}

To compute weights of 7 input with relevance form of feedback, 1st we will be inclined to determined the quantity of education cycles the usage of a grid are seeking technique. The outcomes set up that 690 schooling cycles had all time mistakes. therefore,

\section{Published By:}


we typically usually generally tend to enforced 690 preparation cycle to compute weight with ANNs. supported the ANNs weight \& Garson's additives consequences, we will be inclined to keep in mind that form of positioned up has the remarkable relevancy of all inputs (Fig.5). the form of manual has thirty first relevancy to the amount of remarks. This belief offers precious statistics. to beautify the amount of comments, publications consider inside the form of the courses. picture, hyperlink, status \& video had been kinds in our assessment. concerning type of courses the make a contribution to sort of remarks, the outcomes rectangular degree referred to inside the social control implication section (phase five). the second most big hassle is that the magnificence of the post. In our evaluation, located up commands had been divided into movement (particular provide), product, and idea. because of this, supported those effects, we have a tendency to finish that to provide you severa feedback, the kind and sophistication square degree critical. to appreciate which kind \& sophistication make a payment mainly quantity of remarks, load of every sub input changed into analyze victimisation SVM. the ones sub input variable rectangular degree mentioned within the social control implication phase.

moreover, exam the amount of remarks amongst courses with and whilst not paid advertisements, we will be predisposed to have a look at that courses that used paid advertisements generated one, 401 feedback as of 139 publication, in comparison with 843 remarks whilst not paid advertisements (Fig. 6). every of post that use compensated classified ad generate ten.10 feedback on the commonplace, and each nonpaid placed up generated 1/2-dozen.01 at the common. This quit end result indicates that paid classified ads make a contribution very little to statement hobby. This computation is established with resource the weight of every enter changeable inside the circumstance of amount of commentary. Used of compensated commercials completely consists of a connexion of ten.46 to inspire remarks. type and sophistication region unit much less complex factors that make contributions some of to encouraging comments.

\section{Paid ads and Likes}

on concept of network look for improvement, 1, 213 education cycle had been determined to exist optimum (table five). once playacting ANN assessment, we have a propensity to magazine dominate donations to kind of like pro every periodical. Therefore, we have a tendency to complete this victimization paid commercials and deciding on the best kind and sophistication of guide may appreciably increase the amount of likes. Contribution of paid commercials to kind of likes. used Garson's algorithmic rule to interpret the facts; the results ar confirmed in Fig. 7. form of publication come to be dominant for the amount of likes. This result modified into properly-attempted via using the ANN enter variable coefficient. sort of publication contributed twenty four. $06 \%$ of the quantity of likes, accompanied by manner of paid classified ads in second place with nineteen. $51 \%$. This surrender result indicates that in helping range of likes, paid classified ads perform better than supporting comments. moreover, supported contrast outcomes from 139 guides with paid classified ads and 139 publications at the same time as no longer paid commercials, guides with paid classified ads generated thirty 755 standard likes and earned 235 likes for each e-bookebook at the not unusual, in evaluation with twenty, 458 overall likes and 147 likes for each e-book on the common for publications at the same time as now not paid advertisements. This suggests that paid classified ads deliver 59 a ramification of likes. magnificence of ebook gives seventeen. $99 \%$ connectedness for fashion of likes. so we're able to end that paid advertisements, type, and sophistication of

\section{Paid ads and Shares}

Much like the preceding experiments, grid evaluation have turn out to be accomplished to are in search of for out the top-notable parameters. because of this, 1735 education 
cycles with zero.029 root propose rectangular errors were determined to be maximum powerful (table 6). The weights of the seven inputs place unit tested in decide nine. splendor of e-eebook had a large feature in supporting the quantity of shares of every publication. the relationship of class eamed twenty first significance; paid commercials supplied a 15 .fifty five $\%$ contribution to the amount of stocks. We idea of 139 publications with paid classified ads and 139 publications on the equal time as now not paid classified ads. The 139 posts with paid commercials cause 4,517 shares, an average of thirty forty nine stocks. For nonpaid publications, three 489 shares had been collected as natural percent gain, a mean of twenty five. 01 shares (decide 10). the opportunities of paid and nonpaid publications were pretty close to. The difference amongst paid and nonpaid courses in terms of percentage numbers end up eight stocks at the commonplace. the development of ebook with paid advertisements changed into twenty nine.forty six $\%$ relative to nonpaid e-bookeeebook. Paid advertisements had a fifteen fifty five $\%$ percentage of importance with reference to shape of stocks.We can't finish that paid packaging is

that the simply problem poignant human beings rectangular degree reached by way of employer fb pages. terrific input variables have important roles in courses' not unusual general overall presentation. In conditions of connectedness of 7 input, paid commercials have been not maximum applicable remember helping guides' common normal performance. elements like, kind or beauty of e-bookebook, time of business enterprise business agency enterprise company, and moreover the fashion of fans square degree vital problems. the ones results had been supported via using assessment completed with the resource of Lee et al . exploitation 782 agencies round the arena, they placed this publication to limited hilarity and feeling cared-for produce excessive rendezvous. a few evaluation outcomes incontestible to $\mathrm{fb}$ compensated advertisements paying attention a lot tons much less consumer hobby than did a pal's recommendation. Consequently, packaging thru facebook might not secure the fulfillment of promotional interest. $\mathrm{fb}$ is provided by an device suggestion tool to generate customized classified ad address clients' hobbies; a few clients may be happy to activate such advertisements conjointly can also moreover want to revel in unhappy after they recognize the organization use there as accomplice publicity instrument . here a few cases, clients like buddy classification to compensated packaging . those evaluation effects advocate that agencies need to motive selecting type, class, and time of business company organization, in desire to tough coins on on-line advertisements for enterprise fb pages. favored net web page likes have been a large keep in mind helping style of reached humans along with appointment of an ebook, so maximising

amount enthusiasts is essential. mainly significant input rectangular degree deon-lineated in desk seven.

\section{MANAGERIAL IMPLICATION}

On this section, we have a propensity to recall 139 publication to use compensated commercials plus that we have an study information during SVM weights. This technique modified into enforced to form a social control implication helping paid guides. we commonly tend to deduce since SVM weight outcome to particular deliver (magnificence 1) have best connexion in helping preferred term publish gain, located through inspirations (class 3), product (elegance 2), positioned up month and various factors as represented in Fig. 11. the ones consequences will manual promoting alternatives regarding the way to publish a manual to accumulate as many mother and father as doable. as a stop result, we be able to cease that an permutation of paid classified ad with additionally rating of inputs (Fig.11) provide an vigorous method pro achieving several folks thru business enterprise $\mathrm{fb}$ page. Moreover, near recognize however paid publication might exist superior en route for extend amount of appointments, trendy communications be worn as an label. consequences rectangular degree known in decide twelve. supported the ones effects, we are able to cease that normal net web page likes play an important function in kind of engagements of each paid e book. the ones problems might be accustomed determine but a guide need to be denote and the way to maximize engagement. throughout this example, universal web web page likes is that the maximum large enter, accompanied thru placed up month, kind of publication (recognition), and possibility factors. as a consequence to maximize engagement, a business organization must 1st address getting the excellent viable fashion of web web page likes. technology of net internet web page likes might be a subject for destiny evaluation.

\section{CONCLUSIONS AND FUTURE RESEARCH}

1. Paid commercials make contributions nine.fifty $\%$ of preferred connection for ultra-present day term publish gain. placed up hour, style of guides, and positioned up month have better contributions to popular time frame put up gain. This result offers beneficial facts; in preference to by myself counting on paid classified ads, marketers need to put up the proper fabric on the correct point.

2. publication that use compensated commercials since an way haven't any perceptible effect on shape of feedback. Paid commercials manufacture an average of ten.10 comments to every put up and posts even as not paid classified ads common six.01 comments in keeping with publish. type and sophistication of courses have extra crucial outcomes on comments. therefore, facts the ones factors could probable growth feedback.

3. In phrases of connection, paid commercials useful useful resource the amount of likes higher than total time frame submit acquire, remarks, and stocks and beautify likes through manner of fifty nine on the not unusual.

4. The consequence of compensated classified ad towards sort of stocks be fifteen.fifty five\%; shares rectangular diploma progressed twenty. 


\section{Paid Promotion on Facebook: AN Analysis Employing a Data Processing Method}

5. forty six\% if paid advertisements rectangular degree used. If we on included to pay hobby on profit of applicable input to type of like, after that elegance of publication be to maximum vital problem near type of sharetherefore, to maximise stocks, groups have to apprehend the class of each placed up in place of completely victimisation paid advertisements as a publication method.

6.This evaluation outcomes suggest that businesses ought to be compelled to recognize their manual. Having paid commercials isn't a terrible method for undertaking capability clients, however combination of compensated ad strategy \& possibility satisfied material material cloth strategies square diploma quite recommended. even though enterprise $\mathrm{fb}$ pages acquire many dad and mom \& produce exceptional appointment, such success perform now not agreement some actual profits or profits. troubles exist in degree everyday overall presentation of such courses in conditions of real earnings because of selling bit factors that have an effect on customers' choices square diploma obscure and hard to are expecting. The bit factors that convert severa patron behaviors into real income need to be studied. Supported such evaluation, the allocation of rate range to unique promoting strategies is probably determined. This method is referred to as promoting attribution. selling attribution for on-line marketing and marketing through company fb pages can be a capability situation rely for destiny assessment.

\section{REFERENCES}

1. Anand, B.N. and Shachar, R., 2009. Targeted advertising as a signal. QME, 7(3), pp.237-266.

2. Bačík, R., Fedorko, R., Kakalejčík, L. and Pudło, P., 2015. The importance of Facebook ads in terms of online promotion. Journal of Applied Economic Sciences, 10(5), p.35.

3. Barbier, G. and Liu, H., 2011. Data mining in social media. In Social Networks data analytics (pp. 327-352). Springer, Boston, MA.

4. Bollen, J., Mao, H. and Zeng, X., 2011. Twitter mood predicts the stock market. Journal of computational science, 2(1), pp.1-8.

5. Cortes, C. and Vapnik, V., 1995. Support-vector networks. Machine learning, 20(3), pp.273-297.

6. Curran, K., Graham, S. and Temple, C., 2011. Advertising on Facebook.

7. International Journal of E-business Development, 1(1), pp.26-33.

8. Garson, G.D., 1991. Interpreting neural-network weights. Al expert, 6(4), pp.46-51.

9. Goh, A.T., 1995. Back-propagation neural networks for modeling complex systems. Artificial Intelligence in Engineering, 9(3), pp.143-151.

10. Hanna, R., Rohm, A. and Crittenden, V.L., 2011. We're all connected: The power of the social media ecosystem. Business Horizons, 54(3), pp.265-273.

11. Krebs, F., Lubascher, B., Moers, T., Schaap, P. and Spanakis, G., 2017. Social Emotion Mining Techniques for Facebook Posts Reaction Prediction. arXiv preprint arXiv:1712.03249.

12. Kriesel, D., 2007. A Brief Introduction on Neural Networks.

13. Krishnan, K.S.T. and Sajilan, S., 2014. The Effects of Social Media on Gen Z's Intention to Select Private Universities in Malaysia. Review of Integrative Business and Economics Research, 3(2), p.466.

14. Lee, D., Hosanagar, K. and Nair, H.S., 2018. Advertising content and consumer engagement on social media: evidence from Facebook. Management Science.

15. Margarida Barreto, A., 2013. Do users look at banner ads on Facebook?. Journal of Research in Interactive Marketing, 7(2), pp.119-139.

16. Misra, B.B. and Dehuri, S., 2007. Functional link artificial neural Networks for classification task in data mining.

17. [17] Moro, S., Rita, P. and Vala, B., 2016. Predicting social media performance metrics and evaluation of the impact on brand building: A data mining approach. Journal of Business Research, 69(9), pp.3341-3351.

18. Needleman, S.E. and Marshall, J., 2014. Facebook ads become costlier choice for small businesses. The Wall Street Journal.
19. Park, J.Y., Sohn, Y. and Moon, S., 2016, March. Power of Earned Advertising on Social Networks Services: A Case Study of Friend Tagging on Facebook. In ICWSM (pp. 299-308).

20. Pelling, E.L. and White, K.M., 2009.

21. Stone, B., 2010. Ads posted on Facebook strike some as off-key. New York Times, 3.

22. Turban, E., Sharda, R., Delen, D., \& Efraim, T. (2011). Decision support and business intelligence systems (9th ed.). Pearson.

23. We Are Social, 2018, "Digital in 2018: World's Internet Users Pass The 4 Billion Mark", https://wearesocial.com/blog/2018/01/global-digital-report-2018 (June 2018).

24. Yuan, S., Wang, J. and Zhao, X., 2013, August. Real-time bidding for online advertising: measurement and analysis. In Proceedings of the Seventh International Workshop on Data Mining for Online Advertising (p. 3). ACM

25. Krebs, F., Lubascher, B., Moers, T., Schaap, P. and Spanakis, G., 2017. Social Emotion Mining Techniques for Facebook Posts Reaction Prediction. arXiv preprint arXiv: 1712.03249

26. Kriesel, D., 2007. A Brief Introduction on Neural Networks.

27. Krishnan, K.S.T. and Sajilan, S., 2014. The Effects of Social Media on Gen Z's Intention to Select Private Universities in Malaysia. Review of Integrative Business and Economics Research, 3(2), p.466.

28. Lee, D., Hosanagar, K. and Nair, H.S., 2018. Advertising content and consumer engagement on social media: evidence from Facebook. Management Science.

29. Margarida Barreto, A., 2013. Do users look at banner ads on Facebook?. Journal of Research in Interactive Marketing, 7(2), pp.119-139.

30. Misra, B.B. and Dehuri, S., 2007. Functional link artificial neural Networks for classification task in data mining.

31. Moro, S., Rita, P. and Vala, B., 2016. Predicting social media performance metrics and evaluation of the impact on brand building: A data mining approach. Journal of Business Research, 69(9), pp.3341-3351

32. Needleman, S.E. and Marshall, J., 2014. Facebook ads become costlier choice for small businesses. The Wall Street Journal.

33. Park, J.Y., Sohn, Y. and Moon, S., 2016, March. Power of Earned Advertising on Social Networks Services: A Case Study of Friend Tagging on Facebook. In ICWSM (pp. 299-308).

34. Pelling, E.L. and White, K.M., 2009. The theory of planned behavior applied to young people's use of social Networksing web sites. CyberPsychology \& Behavior, 12(6), pp.755-759.

35. Stone, B., 2010. Ads posted on Facebook strike some as off-key. New York Times, 3. 